This is a postprint version of the following published document:

Baselga, J., Llorente, M. A., Nieto, J. L., HernándezFuentes, I. \& Piérola, I. F. (1988). Polyacrylamide networks. Sequence distribution of crosslinker. European Polymer Journal, 24 (2), pp. 161-165.

DOI: $10.1016 / 0014-3057(88) 90145-0$
(C) Pergamon Press, 1988
(C) Elsevier

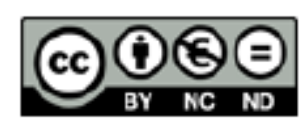

This work is licensed under a Creative Commons Attribution-NonCommercialNoDerivatives 4.0 International License. 


\title{
POLYACRYLAMIDE NETWORKS. SEQUENCE DISTRIBUTION OF CROSSLINKER
}

\author{
J. Baselga, ${ }^{1}$ M. A. Llorente, ${ }^{2}$ J. L. Nieto, ${ }^{3}$ I. Hernández-Fuentes ${ }^{1}$ and I. F. PiÉrola ${ }^{1}$ \\ 'Departamento de Químíca Físíca, Facultad de C.C. Químícas, Uníversídad Complutense, 28040 Madríd Spaín \\ ${ }^{2}$ Departamento de Químíca Físíca, Facultad de Cíencías, UNED, 28040 Madríd Spaín \\ ${ }^{3}$ Instítuto de Estructura de la Matería, CSIC, 28006, Madríd, Spaín
}

\begin{abstract}
The crosslínkíng copolymerízatíon of acrylamíde (AA) and $N, N^{\prime}$-methylene-bís-acrylamíde (BA) has been studíed by hígh resolutíon 'H-NMR wíth copolymerization ín sítu. Thís procedure allows calculation of the copolymer composition at zero degree of conversíon and as a function of the polymerízation tíme. Monomer reactívíty ratíos were calculated by the KelenTüdös method ín the pre-gel state and duríng gelatíon. Sequence dístríbutíons of both comonomers were then characterízed.
\end{abstract}

\section{INTRODUCTION}

This report is part of a project $[1,2]$ with the objective of characterizing the structure of polyacrylamide networks (PAA) obtained by radical copolymerization of acrylamide (AA) and a crosslinker, typically, $N, N^{\prime}$-methylene-bis-acrylamide (BA).

Ideal networks obtained by chain crosslinking copolymerization should be formed by linear chains joined by randomly distributed knots. Real networks have a number of defects with respect to that ideal structure.

(i) Chains between crosslinks may have microheterogeneities formed by a non-random distribution of diastereoisomers. In PAA networks, we have found about $10 \%$ of head-to-head units [1] and predominantly isotactic diads $[1,3]$.

(ii) The crosslinking comonomer is not always joining two different chains; it may also be involved in intramolecular cyclics which are elastically inactive $[4,5]$ or it may react only through one of its unsaturations giving pendant vinyl groups which may or not react later [5-7]. In the system considered here, 7 membered rings may also be formed by reaction of a growing chain with one of the unsaturated groups of a BA molecule, followed by reaction with the other unsaturated group of the same molecule. Such cyclics have been found in soluble BA homopolymers obtained with a redox initiator similar to that employed here [8-9]. Fringes and soluble extractable chains are also elastically ineffective and can be considered as departures from the ideal model.

(iii) Real networks are heterogeneous, showing microdomains with large segmental density joined by chains containing much fewer crosslinker molecules. It results in macroporous structures which give to the network a larger swelling capacity. PAA networks are known to be quite heterogeneous [1] (and references therein). Highly crosslinked regions have been found in PAA gels by several techniques and the size of these regions has been estimated as between $30-500 \mathrm{~nm}$ [10]. It seems now well established that phase separation occurs [4] during the formation of heterogeneous networks. The mechanism of chain crosslinking copolymerization determines also the inhomogeneous distribution of monomomers in the whole volume of the resulting network [4]: the reaction proceeds in three steps, viz. the formation of microgel-like particles, the gelation and the post-gel reaction of pendant unsaturation to form additional crosslinks [6]. For PAA gels, it has been assumed $[1,10]$ that BA aggregates form the nuclei of microgel particles which will give rise to the more compact zones in the network but there is no experimental evidence for such aggregation [1]. We think a better interpretation is that the different reactivities of the comonomers (AA and BA) [9], together with the two general causes of heterogeneity mentioned in the beginning of this paragraph, are responsible for the two-phase structure for the PAA networks.

The different reactivities of the comonomers has two consequences in the resulting polymer composition. On the one hand, both comonomers form sequences with average lengths determined by the monomer reactivity ratios $r_{1}, r_{2}$ [11]. Moreover, this causes a shift of the instantaneous composition of the feed. These will be the aspects considered in this paper for PAA gels. Subsequent contributions [2] will analyze the other causes for heterogeneity (iii) and the formation of intramolecular cyclics and related defects considered in paragraph (ii). All these structural characteristics determine the properties of the PAA gels such as network swelling and elasticity, gel permeability or the diffusion of solutes through the gel.

\section{Reagents}

\section{EXPERIMENTAL}

Acrylamide (AA) and $N, N^{\prime}$-methylene-bis-acrylamide (BA) were high purity Eastman Kodak products; BA was recrystallized from acetone. $\mathrm{D}_{2} \mathrm{O}(99.98 \%)$ was from Scharlau. As initiator, the redox system potassium persulphate (PS)/triethanolamine (TEA) was employed. Both PS and TEA were Carlo Erba products. 
Table 1. Experimental conditions: AA and BA concentrations in $\mathrm{mol} / \mathrm{l}$, total comonomers concentration $\boldsymbol{T}$ in $\% \mathbf{w} / \mathrm{v}$, crosslinker proportion $C$ in $\% \mathbf{w} / \mathbf{w}$ and mole fraction of $\mathbf{B A}$ in the feed $f_{\mathrm{BA}}^{o}$

\begin{tabular}{cccccl}
\hline Experiment No. & {$[\mathrm{AA}](\mathrm{M})$} & {$[\mathrm{BA}](\mathrm{M})$} & $T(\% \mathbf{w} / \mathrm{v})$ & $C(\% \mathrm{w} / \mathrm{w})$ & $f_{\mathrm{BA}}^{o}$ \\
\hline C1 & 0.2634 & 0.1233 & 3.77 & 50.4 & 0.319 \\
C2 & 0.5121 & 0.0915 & 5.05 & 27.9 & 0.152 \\
C3 & 0.5909 & 0.0461 & 4.91 & 14.5 & 0.0723 \\
C4 & 0.0736 & 0.0934 & 1.96 & 73.3 & 0.559 \\
C5 & 0.1791 & 0.0445 & 1.96 & 35.0 & 0.199 \\
C6 & 1.284 & 0.0740 & 10.3 & 11.1 & 0.0545 \\
\hline
\end{tabular}

\section{${ }^{\prime} H-N M R$ spectra}

Proton NMR spectra were obtained at $360 \mathrm{MHz}$ on a Bruker WM-360 spectrometer in the Fourier mode. Recording conditions were $8 \mu \mathrm{sec}$ pulse width $\left(90^{\circ}\right.$ flip angle), $3000 \mathrm{~Hz}$ sweep width, $16 \mathrm{~K}$ points and 13 scans. A relaxation delay of $20 \mathrm{sec}$ between pulses was used to ensure that quantitative signals from the differently relaxing protons of both molecules were obtained.

The kinetics were followed by running several spectra in a $10 \mathrm{hr}$ period, followed by plotting the integral curve corresponding to monomer signals on a suitable scale. Although the $-\mathrm{CH}_{2}-$ bridge signal from the network overlaps with that of the methylenic protons of the BA comonomer, there is no problem in the integration because of the very different line widths of the two signals, the former being lost in the noise unless high temperature is reached. The temperature was maintained at $22^{\circ} \mathrm{C}$ using the standard Bruker accessory.

\section{Sample preparation}

The sample preparation, as well as the necessary manipulation in order to maintain the solvent residual signal at a minimum, have been described [1].

Concentrations used for the initiator system were $[\mathrm{PS}]=6.57 \cdot 10^{-3} \mathrm{M}$ and $[\mathrm{TEA}]=1.12 \cdot 10^{-3} \mathrm{M}$. Six copolymerizations were run as a set, varying the overall comonomer concentration and crosslinking agent proportion. The experimental conditions are summarized in Table 1 .

\section{RESULTS AND DISCUSSION}

The chain crosslinking copolymerization of AA and BA has been studied by means of high resolution ${ }^{1} \mathrm{H}-\mathrm{NMR}$. From the time evolution of the integral curve corresponding to monomer signals, the AA and BA degrees of conversion $\left(\alpha_{A A}, \alpha_{B A}\right)$ can be obtained as a function of time [1]. Protons in the polymer structure give very broad signals which are incorporated in the base line, unless high temperature is reached. This indicates that very compact microgel particles are formed from the very beginning of the reaction.

Figure 1 represents the total degree of conversion $\left(\alpha_{T}\right)$ as a function of the polymerization time for experiments described in Table 1. $\alpha_{\mathrm{AA}}$ and $\alpha_{\mathrm{BA}}$ have similar shape with $\alpha_{\mathrm{BA}}$ always larger than $\alpha_{\mathrm{AA}}$. The point at which the slope (i.e. the polymerization rate) increases abruptly has been taken as the gel point $[1,2,12-14]$. The instant copolymer composition $\left(F^{\text {inst }}\right)$ and the composition of the remaining mixture of comonomers ( $\left.f^{\text {inst }}\right)$, in mole fractions, may be calculated with the expressions:

$$
F_{\mathrm{BA}}^{\mathrm{inst}}=\frac{\mathrm{d} \alpha_{\mathrm{BA}} / \mathrm{d} t}{\mathrm{~d} \alpha_{\mathrm{T}} / \mathrm{d} t} f_{\mathrm{BA}}^{o}
$$

$$
f_{\mathrm{BA}}^{\mathrm{inst}}=\frac{\alpha_{\mathrm{BA}}-1}{\alpha_{\mathrm{T}}-1} f_{\mathrm{BA}}^{o}
$$

where the superscript $o$ means value at $t=0$. Figure 2 shows the dependence of $F_{\mathrm{BA}}^{\text {inst }}$ on $f_{\mathrm{BA}}^{\text {inst }}$ in two different steps of the reaction: viz. initially $(t=0)$ and when $\alpha_{\mathrm{T}}=0.35$ and all the samples are in the gelation process (Fig. 1). It is clear from Fig. 2 that the polymers formed in those two stages of the polymerization have different compositions and therefore different structures, in accordance with the heterogeneous character of PAA networks.

Copolymer compositions are governed by the reactivity ratios. We have calculated with data from Fig. $2, r_{1}$ and $r_{2}(1 \equiv \mathrm{AA}, 2 \equiv \mathrm{BA})$ in the pre-gel state and during gelation by the method of Kelen-Tüdös [15]. By using instant values of $F$ and $f$, we eliminate the usual factors which introduce systematic errors in $r_{1}$ and $r_{2}$ [16]. Figure 3 shows how the two Kelen-Tüdös plots are parallel and have different intercepts. In consequence, the reactivity ratio $r_{1}$ does not change appreciably during the polymerization while $r_{2}$ is during gelation about half of the initial value (Table 2).

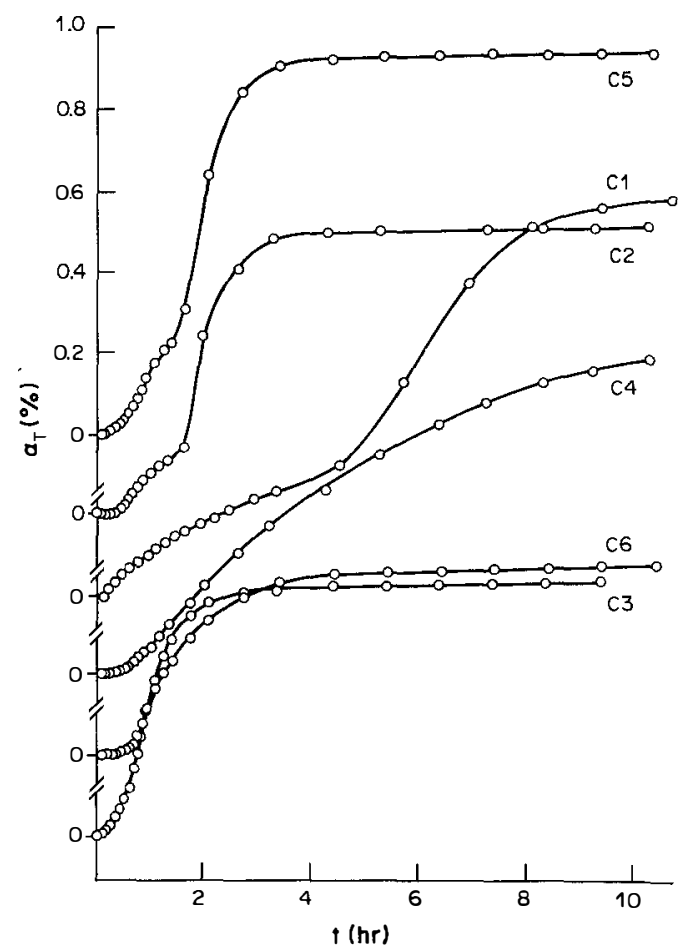

Fig. 1. Total degree of conversion as a function of polymerization time in the six experiments described in Table 1. 


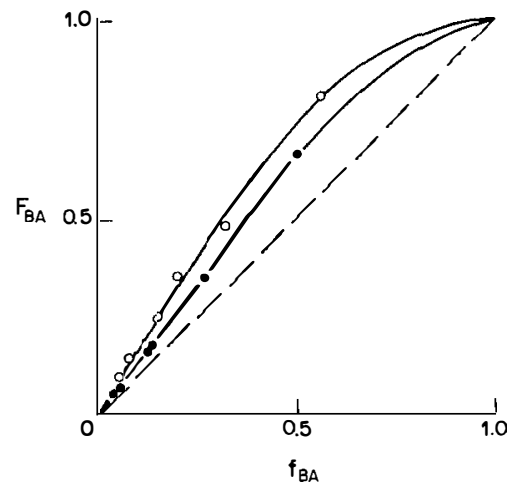

Fig. 2. Instant molar fraction of $\mathbf{B A}$ in the feed $\left(f_{\mathbf{B A}}\right)$ and in the resulting copolymer $\left(F_{\mathrm{BA}}\right)$ at $(O) \alpha_{\mathrm{T}}=0$ and (O) $\alpha_{\mathrm{T}}=0.35$.

After consideration of the possible influence of the gel effect on $r_{1}$ and $r_{2}$ in vinyl-vinyl copolymerizations showing the Trommsdorf effect, it has been concluded that in such systems: the monomer reactivity ratios remain constant at high conversions [22] and therefore we expect also that terminations are chemically controlled reactions and $r_{1}$ and $r_{2}$ are not influenced by the increased viscosity during gelation. The change that we have observed can be related to the existence of phase separation during the polymerization [23] or better to different reactivities of the unsaturated groups in BA [5]. The Kelen-Tüdős method or any other similar linearization of the Mayo-Lewis equation has been widely applied to monovinyl-divinyl systems $[4,5,13,17-20]$. Such treatment implicitly assumes that the reactivities of the vinyl groups in the crosslinker are identical and independent. This hypothesis can be considered valid at $t=0$ but, once one of the vinyl groups of the crosslinker has reacted, the reactivity of the other changes [5]. In vinyl-vinyl copolymerizations, the influence of the dilution of comonomers is not considered but in chain crosslinking copolymerizations it greatly influences the formation of intramolecular cyclics and therefore the reactivity of the whole system [2]. Taking into account all those limitations, we must consider $r_{1}$ and $r_{2}$ during gelation $\left(\alpha_{\mathrm{T}}=0.35\right)$ as apparent values with $r_{2}$ representing an average for the two unsaturated groups.

Table 2 compares the $r_{1}$ and $r_{2}$ values for the system AA/BA with those for similar systems. A large tendency of the crosslinking comonomer to react with

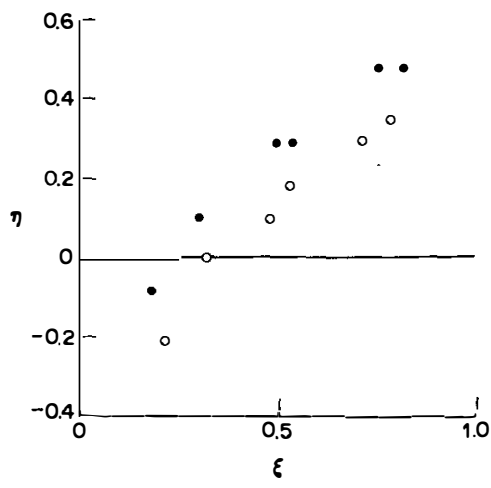

Fig. 3. Kelen-Tüdős plot for $(O) \alpha_{\mathrm{T}}=0$ and $(\Theta) \alpha_{\mathrm{T}}=0.35$.

itself is generally observed unless steric effects make it difficult.

The different reactivities of AA and BA determine that the crosslinker is not randomly distributed along the chains but forms sequences with length given by

$$
l_{\mathrm{BA}}=1+r_{\mathrm{AB}} \frac{f_{\mathrm{BA}}}{f_{\mathrm{AA}}}
$$

Figure 4 shows the dependence on $f_{\mathrm{BA}}^{\text {inst }}$ of average sequence lengths for $\mathrm{AA}$ and $\mathrm{BA}$ and $R$, the number of sequences per 100 monomer units calculated as in Ref. 24

$$
R=\frac{200}{2+r_{\mathrm{AA}} \frac{f_{\mathrm{AA}}}{f_{\mathrm{BA}}}+r_{\mathrm{BA}} \frac{f_{\mathrm{BA}}}{f_{\mathrm{AA}}}}
$$

Even with very low $f_{\mathrm{BA}}$ values, BA forms sequences containing more than 1 monomeric unit $\left(l_{\mathrm{BA}}>1\right)$. Therefore it is not $100 \%$ efficient from the point of view of the hyrogel elasticity: for example, a BA dyad is only a 6-functional crosslink whereas two isolated BA units may become two crosslinks 4-functional each. Larger sequences behave also as multifunctional knots with crosslinking efficiency progressively smaller with respect to isolated BA units. The probability of BA pentads or other sequences of 5 monomer units centered in BA depends on the monomer reactivity ratios (through $R$ ) and on the instant composition of the copolymer $F_{\mathrm{BA}}$. In Table 3 we have calculated the fraction of several pentads through its relationship with the probability $P_{\text {BA }}$ that a given BA unit has an AA on one side [24].

Table 2. Monomer reactivity ratios of several chain crosslinking polymerizations

\begin{tabular}{lccccc}
\hline Comonomer 1 Comonomer 2 & $r_{1}$ & $r_{2}$ & $T\left({ }^{\circ} \mathrm{C}\right)$ & Solvent & Reference \\
\hline Acrylamide $N, N^{\prime}$-Methylene-bis-acrylamide & & & & & \\
$\alpha_{\mathrm{T}}=0$ & 0.57 & 3.36 & 22 & $\mathrm{H}_{2} \mathrm{O}$ & This work \\
$\alpha_{\mathrm{T}}=0.35$ & 0.64 & 1.77 & 22 & $\mathrm{H}_{2} \mathrm{O}$ & $\mathrm{This}$ work \\
Styrene Divinylbenzene (DVB) & 0.38 & - & 60 & $\mathrm{Bz}$ & 18 \\
Styrene Divinylbenzene $m$-DVB & 0.54 & 0.58 & 60 & $\mathrm{Bz}$ & 21 \\
Styrene Divinylbenzene $p$-DVB & 0.15 & 1.22 & 60 & $\mathrm{Bz}$ & 21 \\
Styrene Divinylbenzene Ethylene-dimethacrylate & 0.42 & 0.37 & 75 & $\mathrm{Bulk}$ & 4 \\
Acrylonitrile $N, N^{\prime}$ Methylene-bis-acrylamide & 0.64 & 1.50 & 30 & $\mathrm{H}_{2} \mathrm{O}$ & 20 \\
$\quad N, N^{\prime}$-Isopropylidene-bis-acrylamide & 0.57 & 2.44 & 60 & $\mathrm{MeOH}$ & 17 \\
Styrene $N, N^{\prime}$-Isopropylidene-bis-acrylamide & 1.57 & 0.565 & 60 & $\mathrm{MeOH}$ & 17 \\
\hline
\end{tabular}

$\mathrm{Bz}=$ Benzene

$\mathrm{MeOH}=$ Methanol 


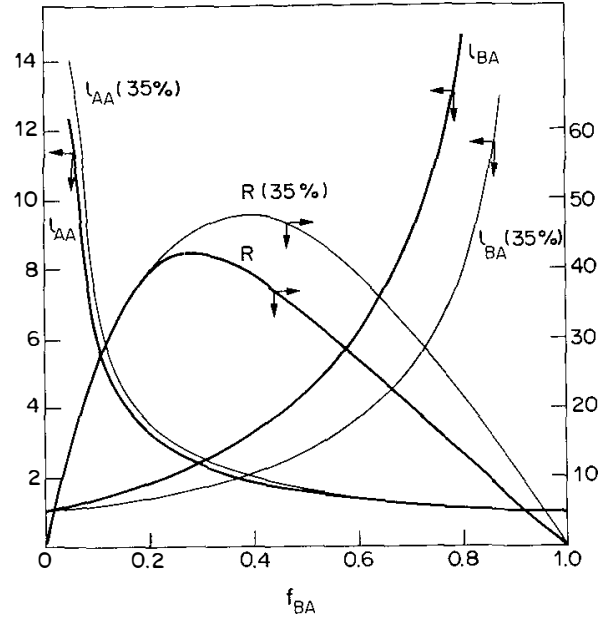

Fig. 4. Mean number of $A A$ and $B B$ units that form sequences $\left(l_{\mathrm{AA}}, l_{\mathrm{BA}}\right)$ at $\alpha_{\mathrm{T}}=0$ and $\alpha_{\mathrm{T}}=0.35$. $R$ represents the number of sequences per 100 monomer units.

The necessary $F_{\mathrm{BA}}$ values corresponding to each $f_{\mathrm{BA}}$ are calculated by means of the Skeist formula.

$$
P_{\mathrm{BA}}=\frac{R}{200 F_{\mathrm{BA}}}
$$

Similarly [24]

$$
P_{\mathrm{BB}}=\frac{\left(F_{\mathrm{BA}}-R / 200\right)}{F_{\mathrm{BA}}}
$$

and

$$
P_{\mathrm{AA}}=\frac{\left(F_{\mathrm{AA}}-R / 200\right)}{F_{\mathrm{AA}}}
$$

In the initial stages of the reaction $\left(\alpha_{T}=0\right)$ even with very low proportions of crosslinker, significant fractions of knots with more than one BA unit are formed. For example (see Table 3) in the initial polymer chains of a standard gel, obtained with an initial BA composition $f_{\mathrm{BA}}^{o}=0.05,60 \%$ of the BA units form monofunctional knots and $40 \%$ BA form knots of larger functionality. Those $n$-functional knots initally formed may result in $n$ pendant unsaturated groups attached together to the main chain which can give rise to $(n+1)$ side chains per knot.

In consequence, compact zones are formed around those knots. Increasing $f_{\mathrm{BA}}^{o}$, the probability of longer BA sequences increases also, and therefore, more concentrated particles are formed initially. During gelation, much shorter sequences of BA are formed for two reasons: $f_{\mathrm{BA}}^{\text {inst }}$ is small to $f_{\mathrm{BA}}^{o}$ and the monomer reactivity ratio $r_{2}$ is also smaller than $r_{2}^{o}$.
The results shown in Table 3 are in accordance with the usual interpretations of microphase separation in poly(acrylamide-co-bisacrylamide) gels $([25,26]$ and references therein).

\section{CONCLUSIONS}

BA has a large tendency to react with itself rather than with AA but AA prefers to react with BA. As a consequence, BA tends to form sequences longer than one even with very low contents of BA in the feed. These sequences behave like multifunctional knots for which crosslinking efficiency is smaller than for the same number of isolated BA units. The length of BA sequences increases with $f_{\mathrm{BA}}$ and is smaller in chains formed during gelation than in the initial stages. Multifunctional knots may give rise (if pendant unsaturated groups react) to side chains and therefore produce microdomains of large segmental density which have been observed by several techniques. The percentage of knots of $n$-functionality can be estimated from the composition of the feed.

Acknowledgement-Financial support from CAICYT (Spain) under Grant No. 0528/84 is gratefully acknowledged.

\section{REFERENCES}

1. J. L. Nieto, J. Baselga, I. Hernández-Fuentes, M. A Llorente and I. F. Piérola. Eur. Polym. J. 23, 551 (1987).

2. J. Baselga, I. Hernández-Fuentes, I. F. Piérola and M. A. Llorente. Macromolecules. In press.

3. (a) M. K. Gupta and R. Bansil. J. Polym. Sci., Polym. Phys. Edn 19, 353 (1981); (b) Y. Inoue, T. Fukutomi and R. Chûjô. Polym. J. 15, 103 (1983)

4. K. Dusek and J. Spevácek. Polymer 21, 750 (1980)

5. K. Dusek. Dev. Polym. 3, 143 (1982).

6. G. Hild, R. Okasha and P. Rempp. Makromolek. Chem. 186, 407 (1985).

7. J. P. C. Bootsma, B. Eling and G. Challa. React. Polym. 3, 17 (1984).

8. A. Gopalan, P. Venuvanalingam, S. P. Manickam, K. Venkatarao and N. R. Subbaratnam. Eur. Polym. J. 18, 531 (1982).

9. A. Gopalan, S. Paulrajan, N. R. Subbaratnam and K. V. Rao. J. Polym. Sci., Polym. Chem. Edn 23, 1861 (1985).

10. T. P. Hsu and C. Cohen. Polymer 25, 1419 (1984).

11. E. T. Hsieh and J. C. Randall. Macromolecules 15, 1402 (1982).

12. A. M. Fernández, J. M. Widmaier, L. H. Sperling and G. D. Wignal. Polymer 25, 1718 (1984).

13. G. Hild and R. Okasha. Makromolek. Chem. 186, (a) 93, (b) 389 (1985).

14. J. Kopecek and H. Bazilova. Eur. Polym. J. 10, 465 (1974)

Table 3. Fractions of pentads centered in the crosslinker as a function of $f_{\mathrm{BA}}$ and $\alpha_{\mathrm{T}}$

\begin{tabular}{lccccccccc}
\hline & \multicolumn{3}{c}{$f_{\mathrm{BA}}^{o}, \alpha_{\mathrm{T}}=0$} & \multicolumn{5}{c}{$f_{\mathrm{BA}}^{\text {nst }}, \alpha_{\mathrm{T}}=0.35$} \\
Pentad* & 0.005 & 0.05 & 0.10 & 0.30 & 0.50 & 0.005 & 0.05 & 0.50 \\
\hline AABAA $P_{\mathrm{BA}}^{2} P_{\mathrm{AA}}^{2}$ & 0.950 & 0.603 & 0.369 & 0.054 & 0.007 & 0.966 & 0.715 & 0.015 \\
ABBAA & $2 P_{\mathrm{BA}}^{2} P_{\mathrm{AA}} P_{\mathrm{BB}}$ & 0.032 & 0.200 & 0.242 & 0.112 & 0.029 & 0.017 & 0.132 & 0.059 \\
AABBA & - & 0.017 & 0.040 & 0.058 & 0.031 & - & 0.006 & 0.059 \\
ABBBA $P_{\mathrm{BB}}^{2} P_{\mathrm{BA}}^{2}$ & - & 0.006 & 0.030 & 0.170 & 0.210 & - & 0.001 & 0.167 \\
BBBBA $2 P_{\mathrm{BB}}^{3} P_{\mathrm{BA}}$ & - & - & 0.006 & 0.124 & 0.356 & - & - & 0.119 \\
ABBBB & - & - & - &
\end{tabular}

* $\mathrm{B}=N, N^{\prime}$-methylene-bis-acrylamide; $\mathrm{A}=$ acrylamide 
15. T. Kelen and F. Tüdős. J. Macromolec. Sci. Chem. A9, 1 (1975).

16. F. L. M. Hautus, H. N. Linssen and A. L. German. J. Polym. Sci., Polym. Chem. Edn 22, 3487 (1984).

17. D. L. Murfin, K. Hayashi and L. E. Miller. J. Polym. Sci. Part A 1 8, 1967 (1970).

18. R. Okasha, G. Hild and P. Rempp. Eur. Polym. J. 15, 975 (1979)

19. K. Dusek. Collect. Czech. Chem. Commun. 34, 1891 (1969).

20. A. Hunyar and E. Roth. Faserforsch. Textiltech. 8, 99 (1957).

21. J. Malinsky, J. Kablan and K. Dusek. Collect. Czech. Chem. Commun. 34, 711 (1969).

22. J. Stejskal, P. Kratochvil, D. Straková and O. Procházka. Macromolecules 19, 1575 (1986).

23. V. A. Myagchenkov and S. Ya. Frenkel. Usp. Khim. 42 , 827 (1973).

24. H. J. Harwood and N. M. Ritchey. J. Polym. Sci., Polym. Lett. 2, 601 (1964).

25. R. Bansil and M. K. Gupta. Ferroelectrics 30, 63 (1980).

26. E. Geissler and A. M. Hecht. In Physical Optics of Dynamic Phenomena and Processes in Macromolecular Systems, (Edited by B. Sedlácek). Walter de Gruyter, Berlin (1985). 